\title{
DESIGUALDADE SOCIAL E SUBJETIVIDADE REVOLUCIONÁRIA: OS DESAFIOS DO TRABALHO DA PSICOLOGIA NO CRAS
}

\author{
SOCIAL INEQUALITY AND REVOLUTIONARY SUBJECTIVITY: THE CHALLENGES OF \\ PSYCHOLOGY WORK AT THE CRAS
}
DESIGUALDAD SOCIAL Y SUBJETIVIDAD REVOLUCIONARIA: LOS DESAFÍOS DEL TRABAJO DE LA PSICOLOGÍA EN EL CRAS

\author{
Ana Flávia de Sales Costa* \\ Michele de Castro Caldeira ${ }^{* *}$
}

\begin{abstract}
RESUMO
Com a implantação do SUAS, a Assistência Social passou por importantes reformulações, as quais têm alterado não somente o padrão de funcionamento da política pública, mas também requerem novas formas de organização e trabalho, novos papéis e competências dos atores sociais nela envolvidos. Com isso, o profissional da Psicologia passa a ser requisitado para contribuir com seus conhecimentos e métodos de trabalho. Inserção que trouxe inquietações e desafios no exercício profissional para os psicólogos e psicólogas no campo da política de Assistência Social. Neste artigo, pretendemos refletir sobre a importância do trabalho da Psicologia no CRAS, tomando a subjetividade revolucionária como seu lócus específico de atuação no enfrentamento da desigualdade social. Para isso, buscamos os pressupostos teóricos da Psicologia sócio-histórica, por meio de conceitos como sofrimento éticopolítico e subjetividade revolucionária, elaborados por Bader Sawaia, que estuda o processo dialético exclusão-inclusão, inspirada nas teorias de Vigotski e Espinosa.
\end{abstract}

Palavras-chave: Psicologia sócio-histórica. Desigualdade social. Subjetividade revolucionária. CRAS. Transformação social.

\begin{abstract}
With the implementation of Unified Social Assistance System (SUAS - Portuguese acronym), the Social Assistance went through important reformulations, which have changed the operational standard of the public policy, and have been demanding new forms of organization and work, new roles and competence from participating social actors. On the top of that, Psychology workers have been required to contribute with their knowledge
\end{abstract}

\footnotetext{
"Doutoranda do Programa de Pós-Graduação em Psicologia da PUC Minas, bolsista CAPES, psicóloga do CRAS desde 2004.

* Doutoranda do Programa de Pós-Graduação em Psicologia da PUC Minas, bolsista CAPES, psicóloga do CRAS no período de 2007 a 2013.
} 
and working methods. An Insertion that brought concerns and challenges in the psychologists' professional practice in the field of social assistance policy. In this article, we intend to bring into light the importance of the Psychology work at the SARC, taking the revolutionary subjectivity as its specific locus of action when coping with social inequality. With this in mind, we have turned to the theoretical assumptions of sociohistorical Psychology, through concepts such as ethical-political distress and revolutionary subjectivity, elaborated by Bader Sawaia who studies the dialectical exclusion-inclusion process, inspired by the theories from Vygotsky and Espinosa.

Keywords: Socio-historical Psychology. Social inequality. Revolutionary subjectivity. SARC. Social transformation.

\section{RESUMEN}

Con la implementación del SUAS, la Asistencia Social ha pasado por importantes reformulaciones que cambiaron no sólo la norma de funcionamiento de las políticas públicas, como también se requieren nuevas formas de organización y trabajo, nuevas funciones y competencias de actores sociales involucrados. Por lo tanto, se pide al profesional de la Psicología que contribuya con sus conocimientos y métodos de trabajo. Inserción que ha traído inquietudes y desafíos en la práctica profesional para el psicólogo en el campo de la política de Asistencia Social. En este artículo, tenemos la intención de reflexionar sobre la importancia del trabajo de la Psicología en el CRAS, tomando la subjetividad revolucionaria como su locus específico de acción para hacer frente a la desigualdad social. Así, buscamos los supuestos teóricos de la Psicología socio-histórica, a través de conceptos como el sufrimiento ético-político y la subjetividad revolucionaria, elaborados por Bader Sawaia, quien estudia el proceso dialéctico de exclusión e inclusión, inspirado en las teorías de Vygotsky y Espinosa.

Palabras clave: Psicología socio-histórica. Desigualdad social. Subjetividad revolucionaria. CRAS. Transformación social.

\section{INTRODUÇÃO}

s transformações no campo da Política Nacional de Assistência Social
(PNAS), reconhecida como Política de Proteção Social (preventiva, proativa
e protetiva), configuraram uma nova situação no Brasil das últimas décadas (Brasil, 2004). Assegurada na Constituição Federal de 1988, ao lado da saúde e da previdência social e, posteriormente, regulamentada pela Lei Orgânica da Assistência Social (LOAS), passou a integrar o Sistema de Seguridade Social. Assinalou-se um período histórico importante para a população que convive com 
a pobreza e sofre as consequências da desigualdade social em nosso País. Pois, ao introduzir em suas disposiçôes gerais o conceito de seguridade social, fez com que a rede de proteção social alterasse o seu enfoque estritamente assistencialista, passando a ter uma conotação ampliada de direito e de cidadania. Nessa trajetória, tem sido feito, sem dúvida, um esforço para superar práticas assistencialistas, de tutela e de marginalização das famílias pobres, em que a desigualdade social é tomada como um problema individual. Estamos caminhando de forma não linear, ora avançando e ora retrocedendo, na compreensão da Assistência Social como um direito e não um favor.

Nesse contexto, a Assistência Social passou a ter a função de garantir o acesso às demais políticas públicas pelas pessoas, famílias e comunidades que se encontram excluídas de seus direitos sociais básicos. O que significa que as provisões assistenciais e as seguranças sociais (segurança de sobrevivência, de acolhida e de convívio ou vivência familiar) afiançadas pelos marcos regulatórios, como a tipificação dos serviços socioassistenciais (Brasil, 2009), devem ser prioritariamente, executadas no âmbito da garantia de cidadania sob a responsabilidade do Estado, cabendo a este a universalização da cobertura e o acesso aos direitos e serviços, programas e projetos.

Com a implantação do Sistema Único de Assistência Social (SUAS), em 2005, a Assistência Social passou por importantes reformulações normativas, as quais têm alterado não somente o padrão de funcionamento da política pública, mas também requerem novas formas de organização e trabalho, novos papéis e competências dos atores nela envolvidos. Uma dessas grandes mudanças foi a organização da Assistência Social em níveis de proteção: proteção social básica (PSB) e proteção social especial (PSE) de média e alta complexidade, além de reorganizar os serviços, programas, projetos e benefícios de acordo com as funções que desempenham, o universo de pessoas que deles necessitam e sua complexidade. Nessa perspectiva, o Centro de Referência da Assistência Social (CRAS) é uma dessas inovações por ofertar os serviços da PSB, de caráter preventivo, em que seu principal núcleo de apoio é a família em seu contexto social.

Tais mudanças abrem um vasto campo de atuação para a Psicologia, que, no início de sua institucionalização no Brasil, apoiou-se em um projeto epistemológico bastante positivista, afastado das temáticas políticas em razão de uma pretensa neutralidade científica. Segundo Bock (2003), a Psicologia esteve associada a projetos modernizadores, de natureza elitista e de corte autoritário. Com a decadência da ditadura militar e com a abertura democrática, novas possibilidades foram criadas para a expressão de uma Psicologia que toma como foco o campo político e o compromisso social. O que vai ao encontro 
da ampliação dos campos de trabalho para psicólogas nas políticas públicas, especialmente por meio dos serviços do SUS e SUAS.

Cabe destacar que a inserção da Psicologia na Assistência Social ainda é um campo em construção e disputa, em que é percebido por muitos como o lugar apenas do assistente social. No entanto se deve considerar que o desenvolvimento da PNAS no Brasil contou com a participação de assistentes sociais e de psicólogas $\mathrm{e}$, recentemente, abriu espaço para outras categorias profissionais, tais como pedagogos, advogados, antropólogos e outros, revelando sua complexidade e interdisciplinaridade.

Refletindo especificamente sobre a Psicologia, de acordo com Bock (1999, p. 324), a identidade do psicólogo está se transformando "na medida em que a realidade objetiva, o mundo social e cultural vem invadindo nosso conhecimento e já não podemos mais falar de mundo psicológico sem considerar o mundo social e cultural". Vai se construindo, assim, um modelo de relação dialética entre esses mundos, o que não significa que já superamos a dicotomia, mas que estamos caminhando. São transformaçôes que implicam mudanças nos processos de trabalho e intervenções sociais, no desenvolvimento de novas competências e saberes. São demandas profissionais que não se restringem a responder a uma lógica mercadológica capitalista e nem reproduzam práticas assistencialistas que impossibilitem a mudança das dimensōes individuais e sociais das pessoas que se utilizam dos serviços públicos.

Por fim, compreendemos que, numa dimensão histórica, os CRAS são unidades recentes no contexto da Assistência Social, o que propicia alguns apontamentos e discussões sobre os desafios que a Psicologia enfrenta nesse espaço. Assim, deparamo-nos com a necessidade de refletir sobre os desafios da Psicologia nesse equipamento público, sem perder de vista o específico da profissão. Dessa forma, este ensaio é de fundamental importância, tendo em vista a proposta interdisciplinar que caracteriza a política de Assistência Social, ressaltando a necessidade de que vários campos de conhecimento se articulem de modo a alcançar resultados mais efetivos perante os problemas sociais locais. Parte-se do pressuposto de que a Psicologia representa um corpus que contribui para repensar as relaçôes sociais e os sujeitos que delas fazem parte.

Daí a importância de a Psicologia se distanciar de práticas que tratam as necessidades sociais como problemas e responsabilidades individuais, sob o risco de limitar suas atividades à "gestão da pobreza". Nessa direção, buscamos refletir sobre os desafios da Psicologia no trabalho no CRAS, não só com os seus saberes teóricos e metodológicos, mas, principalmente, com a compreensão da importância de se resgatar a subjetividade como dimensão fundamental na 
superação da desigualdade no contexto da dialética da exclusão e inclusão (Sawaia, 2009). Problematizamos o conceito de subjetividade conforme propõem Sawaia e Silva (2019), localizando-o numa perspectiva revolucionária, em que o social e o individual sejam compreendidos como uma totalidade. E baseados nessa proposta, apresentamos um debate sobre o trabalho da Psicologia no CRAS, tomando a subjetividade revolucionária como seu lócus específico de atuação no enfrentamento da desigualdade social.

\section{O TRABALHO DA PSICOLOGIA NO CRAS}

Como citado acima, é possível perceber muitos avanços no campo da Assistência Social no Brasil nas últimas décadas, que podem ser vistos em alguns marcos legais, desde a Constituição Federal de 1988, a criação da LOAS, em 1993 (Lei no 8.742/1993), a reformulação da PNAS, em 2004 (Brasil, 2004), culminando com a criação SUAS, no ano de 2005 (Brasil, 2005a; Lei no 12.435/2011).

O SUAS propôs um novo modelo para a política pública de Assistência Social e definiu como referências a vigilância, a proteção e a defesa social e institucional dos direitos dos usuários. Os serviços foram organizados, conforme a sua complexidade, em proteção social básica (PSB), de caráter preventivo, e proteção social especial de média e alta complexidade, destinada aos casos de violação de direitos (Brasil, 2005b).

Foram criados espaços públicos, entre eles o CRAS, unidade pública da $\mathrm{PSB}$, que tem como objetivo prevenir situações de violação dos direitos e de rompimento dos vínculos familiares, mediante a articulação e a prestação de serviços, programas e projetos socioassistenciais. O equipamento deve estar localizado em áreas de maiores índices de vulnerabilidade e risco social e contar com profissionais de nível superior, em especial de Psicologia e do Serviço Social (Lei no 12.435/2011).

$\mathrm{Na}$ prática, o trabalho no CRAS é constituído basicamente por acolhida aos usuários, visitas domiciliares, atendimentos particularizados e em grupos, muitas vezes, descontínuos diante da grande demanda espontânea de atendimento. Engloba ainda a articulação desses serviços, em seu território de abrangência, e uma atuação intersetorial na perspectiva do acompanhamento familiar, que perpassa o desenvolvimento do Serviço de Proteção e Atendimento Integral à Família (PAIF), o Serviço de Atendimento em Domicílio da Pessoa Idosa e com Deficiência e o Serviço de Fortalecimento de Vínculos Familiares e Comunitários (SFVC). 
Tendo em vista que os CRAS têm por direção o desenvolvimento humano e social e a garantia de direitos e condições dignas de vida da população, por meio de trabalhos que promovam as capacidades, o protagonismo e a autonomia das pessoas que acessam os serviços, entende-se, neste estudo, que a atuação da Psicologia tem se configurado como peça fundamental na elaboração e efetivação de políticas públicas na área da Assistência Social. Segundo o Centro de Referência em Psicologia e Políticas Públicas (Crepop) (Conselho Federal de Psicologia [CFP], 2007), os psicólogos e psicólogas nos CRAS devem se voltar para a valorização dos aspectos saudáveis presentes nos sujeitos, nas famílias e na comunidade.

Conforme as orientações técnicas produzidas pelo Crepop (CFP, 2007),

Os psicólogos no CRAS devem promover e fortalecer vínculos socioafetivos, de forma que as atividades de atendimento gerem progressivamente independência dos benefícios oferecidos e promovam a autonomia na perspectiva da cidadania. Atuar numa perspectiva emancipatória, em um país marcado por desigualdades sociais, e construir uma rede de proteção social é um grande desafio (p. 24).

Sabe-se também que nós, psicólogas e psicólogos, fomos convidados a compor as equipes de referência responsáveis pelo atendimento às famílias nos equipamentos, mediante uma proposta de atuação interdisciplinar, na qual assistentes sociais e psicólogos têm a tarefa de buscar compreender a demanda das pessoas, em seus aspectos históricos, sociais, pessoais e contextuais, para se realizar uma intervenção de qualidade capaz de mudar a realidade de milhares de famílias no Brasil. Nesse contexto, nós nos encontramos diante de novo um desafio: experimentar novas possibilidades de atuação nas políticas públicas, a partir das mudanças na Assistência Social brasileira, já que a Psicologia, no início, estabeleceu-se como uma profissão distante das pessoas menos favorecidas social e economicamente, apresentando-se como um instrumento possível e adequado para a intervenção que a elite desenhava nas décadas de 1960 e 1970 (Bock, 2003).

Cabe aqui destacar que, na prática, mesmo sendo produzidos alguns materiais como diretrizes para a atuação tanto do psicólogo quanto do assistente social no CRAS, ainda existe uma grande preocupação em definir o "papel" da Psicologia nesse espaço, devido à imprecisão do marco normativo e à escassez de literatura científica; esta define que as "ações deste profissional devem ser integradas com outros(as) profissionais dentro do serviço, bem como com outros serviços visando o trabalho em rede" (CFP, 2007, p. 33). Assim, o espaço de interseção entre Psicologia e Serviço Social gera inquietação em ambos os profissionais, já que, no manual de orientações técnicas para o CRAS, as funções de psicólogos 
e de assistentes sociais são as mesmas, apontando a realização de um trabalho interdisciplinar ou mesmo transdisciplinar.

Nesse sentido, "A inserção profissional da psicologia neste contexto deve estar calcada numa visão crítica da política de assistência social e em um compromisso com as urgências da sociedade brasileira” (CFP, 2007, p. 21). De acordo com o Conselho Federal de Psicologia (2007), as práticas psicológicas não devem categorizar, patologizar e objetificar a população, mas buscar compreender seus processos, estudando as particularidades e circunstâncias em que ocorrem.

O trabalho da Psicologia no CRAS aponta para a importância da subjetividade e da intersubjetividade no contexto social. Cabe ao psicólogo considerar a "dimensão subjetiva dos sujeitos, favorecendo o desenvolvimento da autonomia e da cidadania" (CFP, 2007, p. 17). Nesse sentido, dentro de uma perspectiva interdisciplinar e uma nova concepção de cidadania, a Psicologia pode contribuir para apoiar e fortalecer o campo da Assistência Social como de direitos. Portanto se tornar necessário para a Psicologia contribuir com seu fazer para a transformação da realidade social brasileira.

Para o Conselho Federal de Serviço Social (2009):

Todas as situações sociais vividas pelos sujeitos que demandam a política de Assistência Social têm a mesma estrutural e histórica raiz na desigualdade de classe e suas determinações, que se expressam pela ausência e precariedade de um conjunto de direitos como emprego, saúde, educação, moradia, transporte, distribuição de renda, entre outras formas de expressão da questão social (p. 5).

Dessa forma, torna-se necessário um trabalho que supere as práticas fragmentadas e promova um encontro entre os vários saberes e que não compartimente os sujeitos dentro da rede de proteção social. Acreditamos que a Psicologia pode oferecer, para a elaboração e execução de políticas públicas de Assistência Social (preocupadas em promover a emancipação social das famílias e fortalecer a cidadania junto a cada um de seus membros), contribuições no sentido de considerar e atuar sobre a dimensão subjetiva dos sujeitos, favorecendo o desenvolvimento da autonomia e cidadania.

A nossa experiência de trabalho e de pesquisa se insere nesse contexto e nos confrontou com os desafios enfrentados pela Psicologia para propiciar, de fato, ações transformadoras da vida das populações que vivem em situação de desigualdade social. Para além das precariedades materiais e simbólicas, chamamnos a atenção os poucos espaços para uma escuta do sofrimento ético-político presente. Sawaia e Silva (2019) indicam o fato de o sofrimento não aparecer como objeto da análise para a intervenção no SUAS, sendo reforçada a dimensão 
do sintoma, da resolução do problema, e não a sua apreensão pelas contradições de sua produção em uma subjetividade histórica.

\section{DIALÉTICA DA EXCLUSÃO E INCLUSÃO: OS EFEITOS DA DESIGUALDADE SOCIAL}

Antes de continuarmos a reflexão sobre a importância de se considerar a subjetividade, no âmbito do trabalho no CRAS, tornar-se necessário aprofundarmos o entendimento a respeito do contexto em que a subjetividade é produzida e, no caso dos sujeitos que acessam os serviços da política de Assistência Social, cabe enfatizar que esse contexto é de desigualdade social.

Segundo Sawaia e Silva (2019), a desigualdade social traz uma problemática psicossocial que é a tensão interna entre o social e o individual e entre a adaptação e a transformação, sendo esta uma das grandes questóes para os profissionais da Psicologia no SUAS. Como articular a dimensão subjetiva da desigualdade sem psicologizar a questão social e como compreender as determinações históricas e sociais sem desconsiderar a atividade singular do sujeito nesse processo? Tal tensão pode ser identificada no questionamento constante de qual seria o papel da Psicologia no campo da Assistência Social e no receio de que, vez por outra é retomado, de que façamos uma clínica tradicional em tais espaços, bem como no dilema sobre até que ponto nossas intervenções visam de fato à transformação ou apenas servem para uma resolução de problemas imediatos sem impacto na estrutura social vigente. Esses são apenas alguns exemplos de como tal tensionamento se manifesta no cotidiano do trabalho no CRAS.

Sawaia (2009) afirma que a desigualdade social desencadeia um tipo de sofrimento específico, nomeado por ela de ético-político.

Em síntese, o sofrimento ético-político abrange as múltiplas afecções do corpo e da alma que mutilam a vida de diferentes formas. Qualifica-se pela maneira como sou tratada e trato o outro na intersubjetividade, face a face ou anônima, cuja dinâmica, conteúdo e qualidade são determinados pela organização social. Portanto, o sofrimento ético-político retrata a vivência cotidiana das questôes sociais dominantes em cada época histórica, especialmente a dor que surge da situação social de ser tratado como inferior, subalterno, sem valor, apêndice inútil da sociedade. Ele revela a tonalidade ética da vivência cotidiana da desigualdade social, da negação imposta socialmente às possibilidades da maioria apropriar-se da produção material, cultural e social de sua época, de movimentar-se no espaço público e de expressar desejo e afeto (Sawaia, 2009, p. 112).

Dessa maneira, pode-se afirmar que o sofrimento ético-político se constitui pela condição social de opressão e se dá devido à desigualdade social, à injustiça e 
à exploração. Segundo Sawaia (2016), esse sofrimento que é vivido pelos sujeitos como perda do futuro, sentimento de desamparo e falta de reconhecimento, indica a experiência de "subcidadania". É importante salientar que a autora escolheu o termo "subcidadania" para referir-se às pessoas que são alvos de políticas públicas, já que o termo revela a contradição que caracteriza tais políticas: a política pública aparece "dilacerada pela atenção entre ser lugar de compensação de baixos salários, e voltada à manutenção da ordem, e ser espaço de autonomia conforme todos nós queremos e viemos trabalhando" (Sawaia, 2016, p. 26). Esse termo denuncia que a lógica da ordem social na desigualdade é a inclusão perversa, o que significa que, no contexto dialético de exclusão e inclusão, a inclusão se dá pela via da exclusão, camuflada na ideologia de que há justiça na desigualdade.

Há que se considerar que, portanto, como forma de manter o sistema em pleno vapor, a sociedade exclui para incluir. Isso significa que a maioria da população se encontra excluída do acesso aos meios de produção material, cultural e social de sua época. Nesse contexto de desigualdade, os governos, por meio das políticas públicas, criam estratégias para que os excluídos sejam inclusos ou se sintam como tal; assim, todos estão inseridos de algum modo. Todavia é importante destacar que Sawaia nomeia essa inclusão de "perversa" (Sawaia, 2003) e também de "ilusória" (Sawaia, 2009), pois essa adaptação faz com que os excluídos, muitas vezes, sintam-se incluídos no circuito produtivo das atividades econômicas, mesmo que seja como mão de obra barata ou reserva, ou simplesmente ao ter acesso aos bens mercadológicos.

Administrar a desigualdade significa, portanto, incluir perversamente e tratar apenas de seus efeitos superficiais, deixando de lado as causas mais profundas da exclusão, reproduzindo novas formas de sofrimento ético-político. A não compreensão da dialética exclusão/ inclusão leva à análise da exclusão, apenas, por meio de índices frios e cálculos complicados, como os que procuram definir se a fronteira entre miséria e pobreza é $R$ \$ 65 ou $R$ \$ 60 (Sawaia, 2003, p. 57).

Compreendendo, a partir da lógica dialética, como nos propõe Vigotski (2000), as políticas de Assistência Social acabam por denunciar a enorme desigualdade da sociedade brasileira e a luta de classes, quando se propõem a enfrentar a questão da distribuição de renda e a oferta de serviços que visem à igualdade e à justiça social, porém sem resolverem o problema estrutural do capitalismo e do neoliberalismo (a dominação de uns sobre os outros em razão do lucro). Além disso, as políticas públicas, elaboradas desde 1988 e reafirmadas especialmente entre 2002 e 2016, são objeto de disputa de classe, pois a diminuição da desigualdade é tomada como perda de privilégios pelas 
classes dominantes. A política pública é, assim, alvo de conflito entre setores da sociedade com interesses divergentes, em que parte defende a cidadania e a igualdade de direito, enquanto outros defendem a concentração de riquezas, o lucro e os privilégios, gerando tensões permanentes entre seus formuladores e operadores.

Nessa perspectiva, pode-se afirmar que, no processo dialético de exclusão e inclusão, a desigualdade social produzida pelo sistema capitalista, patriarcal e colonial tem efeitos na vida das pessoas para além dos econômicos, gerando estratégias de manutenção do status quo pela via da humilhação, do sofrimento ético-político que retira dos sujeitos a potência de ação em favor de melhores condiçôes de existência para si e para os seus, enredando-os numa teia ilusória, em que a garantia dos mínimos sociais e econômicos "parece" atender às suas necessidades, porém não geram condições, de fato, de uma superação da desigualdade.

Sawaia (2016) enfatiza que esse sofrimento, que é da competência de todos os profissionais do SUAS, obriga-nos a uma ação interdisciplinar que não negligencie as condições sociais e individuais dos sujeitos que o vivenciam. Dessa maneira, precisa ser considerado como dispositivo biopolítico que, se por um lado, funciona para a manutenção da opressão, pode, por outro, ser uma via para superação e alcance de autonomia, questão que será discutida a seguir.

\section{SUBJETIVIDADE REVOLUCIONÁRIA E TRANSFORMAÇÃO SOCIAL}

A compreensão de que a dialética da exclusão e inclusão causa sofrimento ético-político aos sujeitos, ao afetar seu cotidiano e suas relações sociais, traz à tona a necessidade de resgatar a subjetividade que ficou envolvida, e até mesmo perdida, nas entrelinhas das análises econômicas e políticas do fenômeno da pobreza e da desigualdade social. Tal resgate implica uma mudança na perspectiva de atuação dos profissionais que atuam na Assistência Social, os quais são convocados a ir além da busca por tratar das questôes objetivas, passando a olhar para a subjetividade como uma dimensão necessária para a superação da desigualdade social.

É preciso frisar ainda que, na teoria sócio-histórica de Vigotski (2000), quando compreendemos que os processos de subjetivação se constituem mediante processos históricos, a neutralidade científica é desconstruída, já que produções acadêmicas são realizadas no curso da história e, portanto, imersas nela, havendo sempre uma intencionalidade. Questionar as naturalizações ou 
legitimá-las é a demonstração de um tipo de compromisso da Psicologia com a transformação ou com a manutenção do status quo. Dessa maneira, a Psicologia sócio-histórica expressa esse compromisso com a transformação da sociedade e com a desalienação doe nosso trabalho, de modo a suscitar posicionamentos em favor da justiça social, os quais são imprescindíveis a uma atuação no CRAS.

Contrária à ideia de que a única preocupação do pobre é com sua sobrevivência biológica, Sawaia (2009) adota a emoção no estudo sobre a exclusão, trazendo assim a ideia de

Humanidade e como temática o sujeito e a maneira como ele se relaciona com o social (família, trabalho, lazer e sociedade), de forma que, ao falar de exclusão, fala-se de desejo, temporalidade e de afetividade, ao mesmo tempo que de poder, de economia e de direitos sociais (p. 98).

Dessa maneira, a autora afirma que se deve buscar recuperar o sujeito perdido nas análises econômicas e políticas, sem perder o coletivo e a responsabilidade do Estado com seus cidadãos.

Nesse âmbito, Sawaia (2009) escolhe a afetividade como categoria analítica e ferramenta da ação transformadora, ampliando a análise da dialética exclusão/ inclusão, já que as emoções podem levar a pessoa a sair da passividade e a ter a potência de ação ampliada. A base motivadora da ação humana ou da não ação é sustentada pela emoção. Portanto, para se trabalhar com a superação da desigualdade social, é preciso trabalhar com a emoção e a criatividade, pois ambas são dimensões ético-políticas da ação transformadora. Dessa forma, essas duas categorias possibilitam "atuar no que há de mais singular da ação política emancipadora" (p. 366).

Outro aspecto importante a ressaltar é que a emoção também é a base que sustenta as relações de poder e opressão, como ainda o processo de resistência. Resgatar a emoção é compreender como os sujeitos que procuram o CRAS são afetados em sua subjetividade pelas ausências às quais estão expostos, quais os recursos têm para o enfrentamento das situações de privação que vivem e, especialmente, como a relação estabelecida entre estes e os profissionais do CRAS provoca emoções. Nesse contexto, a questão-chave está em compreender em que medida o equipamento público do CRAS e as relaçôes sociais construídas nele são capazes de ampliar a potência de ação dos sujeitos (pessoas, famílias e grupos atendidos e profissionais) pelas afetações provocadas.

Tal reflexão torna-se ainda mais importante se retomarmos a discussão sobre o fato de que a população atendida no CRAS é estigmatizada e desqualificada como pobre e sem valor pela sociedade, uma vez que esta valoriza a posse dos 
bens materiais e o consumo. Observa-se, nos atendimentos, que os sujeitos que dependem dos serviços da política de Assistência Social, na maioria das vezes, apresentam sentimento de inferioridade e culpa pela condição na qual se encontram, o que alimenta a impotência diante das adversidades. Assim, a desigualdade social causa sofrimento e um sentimento de responsabilização individual dos problemas de ordem social nos sujeitos, pela condição de exclusão que vivenciam, o que agrava a vulnerabilidade social. Nesse contexto, como lidar com isso?

Sawaia e Silva (2019) apresentam a afetividade como o elemento que possibilita a experimentação do mundo, contendo uma dimensão ética, visto que a emoção é a medida de como somos afetados pelas relaçôes sociais que podem aumentar ou reduzir a nossa potência de vida. Segundo as autoras, a desigualdade social gera e cronifica os afetos tristes, o que retira a potência de ação dos sujeitos e grupos. Como expõem Sawaia e Magiolino (2016):

A desigualdade social se caracteriza por ameaça permanente à existência. Ela cerceia a experiência, a mobilidade, a vontade e impõe diferentes formas de humilhação. Essa depauperação permanente produz intenso sofrimento, uma tristeza que se cristaliza em um estado de paixão crônico na vida cotidiana, que se reproduz no corpo memorioso de geração a geração. Bloqueia o poder do corpo de afetar e ser afetado, rompendo os nexos entre mente e corpo, entre as funções psicológicas superiores e a sociedade (pp. 369-370).

Por isso mesmo, Sawaia e Silva (2019) defendem que temos de mudar a concepção e a forma como a subjetividade é trabalhada, considerando a perspectiva da subjetividade revolucionária construída pela Psicologia sócio-histórica de vertente marxista, em que a determinação social é afirmada compreendendo a passagem do social ao psicológico de forma dialética e processual, sendo a liberdade e a determinação não excludentes.

A subjetividade revolucionária, então, representa, em menor escala, a totalidade das relações sociais vividas historicamente e o modo como cada sujeito as converte em funções psicológicas superiores (Sawaia \& Silva, 2019). Numa crítica interna à Psicologia, Vigotski (2000) converte as relações sociais em funções psíquicas superiores, sendo o sujeito uma unidade articulada por múltiplos elementos. Ele acreditava que a única solução para superar as dicotomias seria transformar conceitos em unidades de sentido (afeto e cognição, mente e corpo, indivíduo e sociedade) (Vygotsky, 2009), não encerrando os construtos em si mesmos, mas articulando-os.

Então, no encontro entre os sujeitos e grupos que buscam o CRAS e o profissional de Psicologia, é preciso compreender que cada subjetividade contém tanto os elementos de seu contexto histórico, as suas sobredeterminações, 
quanto o modo singular como cada uma as vivencia, convertendo-as em suas funções psíquicas, quais sejam a memória, a cognição, o afeto, a linguagem e todas as demais. Há, ao mesmo tempo e dialeticamente, como componentes da subjetividade, as determinações sociais e a liberdade, sendo que o trabalho do psicólogo transita entre essas dimensóes de um mesmo processo.

Com base nessa concepção, Sawaia (2014) propõe que a transformação social necessariamente envolve o engajamento subjetivo, sendo a subjetividade uma das dimensões necessárias aos processos revolucionários, permitindo-nos trazê-la para o campo da Psicologia social, como ciência capaz de contribuir para modos de vida mais justos e dignos. Para além das mudanças estruturais, econômicas e políticas, a dimensão da subjetividade estaria presente como potência e caminho para a transformação no campo da desigualdade social, tornando-se parte necessária à ação da Psicologia no CRAS.

Quando afirmamos a atuação pela via de uma subjetividade revolucionária, estamos dizendo de uma construção relacional, ou seja, afastando-nos da ideia da subjetividade privatizada e psicologizada, e adotando uma visão histórica e construída nas relações sociais, o que, por essa mesma razão, torna-se uma dimensão importante do trabalho em contextos de desigualdade social, visto que toda transformação, em alguma medida, é gerada pelas subjetividades envolvidas no processo, ao mesmo tempo em que estas são, também, transformadas pelo próprio processo de forma dialética e contínua. Nesse movimento histórico, temos a possibilidade de uma atuação que se dê nas intervenções individuais, grupais e comunitárias do CRAS, por meio de afetaçóes capazes de promover potência de ação pelas transformações que podem causar nas subjetividades envolvidas.

\section{CONSIDERAÇŌES FINAIS}

Como proposta inicial deste ensaio, discutimos a importância de (re)pensar o trabalho do psicólogo, da psicóloga no CRAS, especialmente no que tange à sua contribuição para a redução da situação de desigualdade social que marca o serviço e àqueles que dele dependem. Nesse sentido, reafirmamos o pressuposto de que a transformação social é o objetivo maior da Psicologia social e que, para tanto, é preciso continuamente refletir sobre os caminhos e práticas que possam ser mais efetivos nesse propósito de alcançar modos de vida mais dignos para a população como um todo.

Tal preocupação é ainda maior se considerado o contexto contemporâneo capitalista, cujas estratégias cada vez mais perversas de incremento ao consumo, 
de responsabilização do indivíduo e de privatização da vida comum têm enfraquecido o tecido social e tornado a perspectiva da igualdade cada vez mais distante. Vivemos no fio da navalha, entre acreditar na transformação social e na Psicologia como uma potente força a ser somada às demais ou nos manter numa postura conformista, por vezes, acompanhada de culpa. Somos capturados por uma lógica de culpabilização individual e por uma ação técnica que colabora para que estratégias de resistência e luta coletiva não sejam construídas, além de nos manter alienados do jogo de forças, envolvidos no campo da Assistência Social e das políticas públicas como um todo, em que dialeticamente se colocam a luta pela igualdade e a manutenção e defesa de privilégios.

Nesse sentido, o que trazemos para a discussão é a ideia de que nós, psicólogas e psicólogos, devemos pensar uma política pública que não se preste a moldar, reeducar ou dirigir a vida das pessoas, e sim promover sujeitos capazes de refletir e se tornarem agentes participativos em seu processo de desenvolvimento pessoal e na transformação de seus contextos de vida. De forma adjacente, buscar o desenvolvimento das capacidades autônomas do pensar, sentir e agir na tomada de decisões em várias situações da vida. É preciso que sejamos, então, profissionais politicamente comprometidos com as transformações sociais, como mediadores que busquem sempre um espaço de liberdade e invenção de novos processos de subjetivação que sejam revolucionários.

Assim como garantir a escuta do sofrimento ético-político, inerente aos processos de desigualdade social, é preciso refinar nosso olhar para as lutas travadas por essas pessoas pela sobrevivência diária, que revelam a potência criativa presente no enfrentamento dessas situações, salientado, na maioria das vezes, apenas como o espaço da falta. Pensar no acesso à Psicologia pelas pessoas que vivem em tais condições é trabalhar no encontro entre o sofrimento e a perseverança, compreendendo seus contextos específicos, suas práticas culturais e de resistência. Tendo em vista esse contexto, cabe à Psicologia um lócus específico de trabalho no CRAS, atuando em prol de uma subjetividade revolucionária, produzida e produtora de modos de vida outros para, a partir daí, realizar intervençôes capazes de promover condiçôes de vida mais igualitárias pela via das afetações provocadas pelos relacionamentos surgidos. 


\section{REFERENCIAS}

Afonso, M. L. M. (2009). O papel da Psicologia no Centro de Referência da Assistência Social. In 1, Congresso UNA de Psicologia: singularidade e direitos humanos. Belo Horizonte: Centro Universitário UNA-BH.

Afonso, M. L. M., Vieira-Silva, M., Abade, F. L., Abrantes, T. M., \& Fadul, F. M. (2012). A Psicologia no Sistema Único da Assistência Social. Pesquisas e Práticas Psicossociais, 7(2), 189-199.

Bock, A. M. B (1999) A Psicologia a caminho do novo século: identidade profissional e compromisso social. Estudos de Psicologia, 4(2), 315-329.

Bock, A. M. B. (Org.) (2003). Psicologia e compromisso social. São Paulo: Cortez.

Brasil. (2004). Ministério do Desenvolvimento Social e do Combate à Fome. Secretaria Nacional da Assistência Social. Política Nacional de Assistência Social - PNAS. Brasília: MDS.

Brasil. (2005a). Ministério do Desenvolvimento Social e do Combate à Fome. Secretaria Nacional da Assistência Social. Sistema Único de Assistência Social SUAS. Brasília: MDS.

Brasil. (2005b). Ministério do Desenvolvimento Social e Combate à Fome. Norma Operacional Básica do Sistema Único de Assistência Social (NOB/SUAS). Brasília: MDS.

Brasil. (2009). Ministério do Desenvolvimento Social e Combate à Fome. Tipificação Nacional de Serviços Socioassistenciais. Brasília: MDS.

Conselho Federal de Psicologia. (2007). Centro de Referência Técnica em Psicologia e Políticas Públicas (Crepop). Referências Técnicas para atuação dola psicólogola no CRAS/SUAS. Brasília: CFP. Recuperado a partir de http://www. pol.org.br/pol/export/sites/default/pol/publicacoes/publicacoesDocumentos/ cartilha_crepop_cras_suas.pdf

Conselho Federal de Serviço Social. (2009). Parâmetrospara a atuação de assistentes sociais na Política de Assistência Social. Brasília: CFSS. (Série: Trabalho e projeto profissional nas políticas sociais).

Constituição da República Federativa do Brasil (1988). (1988). Brasília: Senado. Recuperado a partir de http://www.planalto.gov.br/ccivil_03/Constituicao/ Constituicao.htm 
Lei no 8.742, de 7 dezembro de 1993. (1993, 7 dezembro). Dispõe sobre a organização da Assistência Social e dá outras providências. Brasília: Diário Oficial da União. Recuperado a partir de http://www.planalto.gov.br/ccivil_03/ Leis/L8742.htm

Lei no 12.435, de 6 de julho de 2011. (2011, 6 julho). Altera a Lei no 8.742, de 7 de dezembro de 1993, que dispõe sobre a organização da Assistência Social. Brasília: Diário Oficial da União.

Sawaia, B. B. (2003). Fome de felicidade e liberdade. In B. B. Sawaia (Org.), Muitos lugares para aprender: Centro de Estudos e Pesquisas em Educação, Cultura e Ação Comunitária - Cenpec. (pp. 53-65). São Paulo: Cenpec, Fundação Itaú Social, Unicef.

Sawaia, B. B. (2009). O sofrimento ético-político como categoria de análise da dialética exclusão/inclusão. In B. B. Sawaia (Org.), As artimanhas da exclusão: análise psicossocial e ética da desigualdade social. Petrópolis: Vozes.

Sawaia, B. B. (2014). Transformação social: um objeto pertinente à Psicologia Social? Psicologia \& Sociedade, 26(núm. esp. 2), 4-17.

Sawaia, B. B. (2016). Conferência de abertura. In Conselho Regional de Psicologia de São Paulo. Psicologia na Assistência Social e o enfrentamento da desigualdade social. (pp. 22-27). São Paulo: CRP-SP. (Cadernos Temáticos CRP-SP).

Sawaia, B. B., \& Magiolino, L. L. S. (2016). As nuances da afetividade: emoção, sentimento e paixão em perspectiva. In L. Banks-Leite, A. L. B. Smolka, \& D. D. Anjos. (Org.), Diálogos na perspectiva histórico-cultural: interlocuçôes com a clínica da atividade. Campinas, São Paulo: Mercado das Letras.

Sawaia, B. B., \& Silva, D. N. H. (2019). A subjetividade revolucionária: questôes psicossociais em contexto de desigualdade social. In G. Toassa, T. M. C. Souza, \& D. J. Rodrigues (Org.), Psicologia sócio-histórica e desigualdade social: do pensamento à práxis. (pp. 23-44). Goiânia: Imprensa Universitária.

Vigotski, L. S. (2000, julho). Manuscrito de 1929. Alexandra Marenitch (Trad.). Educação \& sociedade, 71, 21-44.

Vigotski, L. S. (2009). A construção do pensamento e da linguagem. São Paulo: Martins Fontes. 